THEORIA ET HISTORIA SCIENTIARUM, VOL. VI, N²

Ed. Nicolas Copernicus University 2002

Laura McNamara

\title{
Representing Time: The Language of (un)Certainty in Post-Cold-War Los Alamos
}

\begin{abstract}
Based on ongoing ethnographic research at Los Alamos National Laboratory, this paper explores a shift in constructions of time among nuclear weapons experts. It frames the Laboratory's weapons experts as members of a community of practice organized around the production of confidence in the American nuclear stockpile. Throughout the Cold War, this community's activities were patterned by several interlocking cycles, including the arms race, cycles of weapons acquisition, and most immediately, a local experimental cycle in which the community designed, engineered, and tested prototype nuclear devices. This local experimental cycle also served as a site for renewing the community and its knowledge, as novice experts acquired skills and abilities and seniors reinscribed understandings about how weapons work. However, these cyclical rhythms broke apart as the Cold War ended, leaving the weapons community without the design-and-test cycle as a central point of social organization. This paper argues that in the wake of these changes, local references to time emphasize a shift from cyclical rhythms of renewal to a more linear understanding of time, in which time has become a force for aging and decay.
\end{abstract}

1992 was a tumultuous year for the US nuclear weapons complex. Throughout the Cold War, scientists and engineers at the Los Alamos National Laboratoryone of the world's top nuclear design facilities-had relied on an extensive experimental program to make judgements about the safety, security, and reliability of the weapons they were asked to create and certify. During the arms race, it was not uncommon for a staff member at Los Alamos to invest thirty

career years in the art and science of weapons, relying on a local cycle of designing, testing, and refining prototype devices to gain insight into the complexities of nuclear explosions. But the end of the Cold War brought an end 
to the arms race, and in June of 1992, the federal government canceled all orders for new nuclear weapons. Adding insult to injury, Congress in September ordered a moratorium on nuclear testing. The Laboratory's physicists and engineers found their expensive experiments quite literally suspended, hung up, as test racks were left to rust, abandoned and empty, above the dry, pockmarked landscape of the US nuclear test site in Nevada.

In the past few years, Los Alamos has recovered somewhat from the abrupt termination of its core experimental project. In 1995 the Laboratory's parent organization, the United States Department of Energy (DOE), formally adopted a new, non-test-based regime for producing weapons-related knowledge. Known as "Science-Based Stockpile Stewardship" (SBSS), it is a multimodal program that relies on computer simulations, small-scale nonnuclear and subcritical experiments, destructive and nondestructive surveillance testing of nonnuclear parts, and archived nuclear test data to assess weapon safety, security, and reliability. The Laboratory plays a key role in developing the methods and technologies necessary to make SBSS work; but although the program has given the Laboratory a new mission, the weapons community is still adjusting to the loss of its longstanding experimental program.

Readers who are familiar with recent scholarship in the sociology of science will recognize this topic as similar to the issues in Mackenzie and Spinardi's article on the "uninvention" of nuclear weapons (1995). Stressing the importance of tacit knowledge in weapons work, the authors provocatively suggest that the end of the experimental program might lead to the gradual disappearance of nuclear weapons knowledge as inchoate skills; understandings and abilities atrophy in the wake of the design-and-test moratoria. This paper discusses the same issue from a slightly different perspective, looking at the shift from testing to SBSS by exploring the many references to "time" that appear in documents and discussions about post-Cold-War weapons work at Los Alamos. Like other anthropologists who have studied high-technology organizations (Barley 1988; Buciarelli 1988; Dubinskas 1988; Traweek 1988a and 1988b), I make the argument that taken-forgranted "common sense" notions of time are important points around which local communities of scientific practice are organized (Wenger 1998). This paper, then, explores the changing kaleidoscope of "times" in nuclear weapons work at Los Alamos, describing the (relatively) predictable cycles of the Cold War arms race and then comparing them to the more erratic times of the post-Cold-War era. In describing and comparing these cycles, I argue that the way nuclear weapons experts currently represent time to themselves and to others reveals fault lines of uncertainty that have opened since the end of the design and testing era. Indeed, in the world of nuclear weapons experts, "confidence" and "time" form an intimate partnership, in which the current instability of the latter undermines the certainty of the former. 


\section{Cycles of Cold War Knowledge Production}

Los Alamos is the place where the nuclear age was bom. Located high in the remote reaches of the Jemez Mountains in north-central New Mexico, Los Alamos was chosen during the World War II Manhattan Project as the perfect site for a sequestered laboratory that would serve as the intellectual center for a secret, nationwide effort to create the world's first atomic bomb. Its mission, of course, was successful: in August of 1945, two atomic bombs were dropped in quick succession on the Japanese cities of Hiroshima and Nagasaki, irrevocably changing the way wars would be fought in the future.

As hostilities between the United States and the Soviet Union burgeoned in the postwar era, nuclear weapons became the primary currency of threat as both East and West adopted a policy of developing and diversifying nuclear arsenals to deter enemy attack. A discussion of deterrence theory is not germane to this paper, but I should point out that nuclear deterrence was an odd mixture of credibility and uncertainty, in that both East and West sought to shake the other's strategic and tactical battle confidence by developing and testing credibly terrifying weapons (Cimbala 1998). Within this regime of brinkmanship, the Laboratory itself was in the business of certainty-of making statements, expressed in statistical terminology but based on the weapons community's collective expertise, about the performance and safety of its designs. As one Los Alamos expert put it,

The heart and soul of any successful policy of mutual nuclear deterrence is the certain belief of national leaders that their own and their adversaries' nuclear forces are survivable, are deliverable, and will function as intended under any circumstances... [This belief] rests solely on assurances given to those leaders by scientists, and by the credibility that these scientists have with the leaders (White 1987b: 2)

In other words, the weapons community at Los Alamos not only produced weapons, but credible knowledge about weapons, or nuclear confidence, demonstrating the certainty that American nuclear devices would work destructively if ever used (Gusterson 1996). As we shall see, the weapons community derived expertise and credibility with leaders, and generated nuclear confidence through an ongoing experimental program that allowed its members to continuously reinscribe their knowledge of these devices through designing and testing prototypes (see Congressional testimony and white-paper briefs by Hecker 1987; Birely 1987; and White 1987a, 1987b, 1988). 
Experts at Los Alamos produced many credibly threatening weapons and an immense body of weapons-related knowledge through hundreds of iterations of a local experimental cycle that consisted of designing, engineering, and testing prototype nuclear explosive devices. This experimental cycle might begin with an idea for a new design, or a modification to an existing design; a question about the effects of a nuclear explosion on a particular piece of military hardware; or the performance of a stockpiled design under hostile conditions. Toward the Cold War's end, bringing these ideas to fruition could require anywhere from six months to five years of intensive work, depending on the complexity of the shot being fired, as staff members designed and built an experimental device that would be detonated at the US nuclear test site in Nevada. This meant putting together a multidisciplinary team of theoretical and experimental physicists, materials experts, mechanical, electrical, and chemical engineers, and machinists and technicians. Preparing for a test involved continuous negotiations and careful scheduling of tasks, as members of this team turned design plans into working devices, chose appropriate diagnostic technologies for data collection, prepared a test hole, and transported the device to the Nevada Test Site (Wolff 1977; LLNL 1985; U.S. Congress Office of Technology Assessment 1989). The subsurface test shot itself was the apex of this cycle (Gusterson 1996); fired from a safe distance, a powerful device could send massive seismic ripples through the desert floor and would frequently result in the formation of a crater above the point of the explosion.

Testing "time" never stopped. For one thing the stockpile required constant monitoring and renewal. Throughout the Cold War, US nuclear defense strategists pursued a program of continuously updating and modernizing the nation's nuclear weapons (Van Cleave and Cohen 1987: ix). Certain materials and components in the devices were vulnerable to age, which could affect their overall performance. Weapons were generally expected to function for 15 to 20 years in the stockpile before they were considered too old, at which point they were retired from service, dismantled, and replaced by a new, updated system, so that the average age of the stockpile was never more than 15 years (Johnson et al. 1996: 18). Because it could take years to develop a functioning nuclear weapon, the Laboratory was constantly involved in monitoring existing systems; modifying, testing and replacing aging parts as necessary; and developing new systems in anticipation of the eventual retirement of existing ones.

All these activities relied on the design-and-test cycle, a single iteration of which could take three to five years of work. Moreover, answering any single question about a nuclear system could require several iterations of the design- and-test cycle, depending on the complexity of the experiments and the types of data collected in each test event. Individual iterations of the design-and-test cycle overlapped, so that for every shot that made it to the test site, waiting in the 
Laboratory's wings were other experimental projects in various stages of development. In other words, there was a constant flow of work, a recycling of the same process several times per year, year in and year out, so that the activities and skills involved in testing were constantly being exercised on the various experiments that were ongoing at any one point.

The pace of this local design-and-test cycle waxed and waned in tandem with the shifting demands of the US defense establishment, whose policymakers hammered out the requirements for maintaining a stable nuclear deterrent, and then worked with the Laboratory to translate policy objectives into weapons technologies. These requirements shifted according to the exigencies of the bilateral arms race, which was at its most intense in the 1950s and the 1960s, calmed briefly with detente in the 1970s, and intensified again in the early 1980s before slowing toward the end of the decade and grinding to a halt in the 1990s. As the pace of the arms race waxed and waned, so too did the demand for new weapons systems and, in turn, the pace at which the Laboratory designed and tested prototype devices. Indeed, Cold War "time" can usefully, if somewhat simplistically, be represented as a set of interlocking, mutually reinforcing cycles: the pace of arms race influencing the rate at which policymakers sought to acquire new weapons systems to maintain the nuclear deterrent; the rate of weapons acquisition setting the pace for the Laboratory's work schedule; and the rate of deploying new weapons affecting, in turn, the intensity of the arms race.

\section{Making Weapons, Making Knowledge, Making Experts}

The design-and-test cycle was as much a social activity as it was a technical one. In this regard, it is helpful to think of Los Alamos as a community of practice (Lave and Wenger 1991; Wenger 1998) organized around a core axis: namely, the production of knowledge through the design and testing of nuclear devices. As we have seen, the Cold War weapons programs not only created a massive stockpile of nuclear weapons; they also organized social relations among the hundreds of staff members involved in weapons work. But the design- and-test cycle also acted as a mechanism for reproducing in neophytes the skills, understandings, and sensitivities necessary to become competent practitioners of weapons work, while it simultaneously provided a site for experienced weaponeers to demonstrate their mastery of weapons-related knowledge.

The cycles of the Cold War marked seasons of renewal for weapons and experts alike, so that in cyclically renewing the stockpile, the community renewed itself. As Traweek (1988b) has pointed out, scientific communities cannot reproduce biologically and must rely on an extensive process of socialization to replicate local cultures of practice in new generations of researchers. As in other 
communities of scientific practice, neophyte weaponeers at Los Alamos acquired a sense of how to do weapons work through participating in the design-and-test cycle, learning not just technical skills, but a locally significant array of understandings, sensibilities, practices, intuitions, language, and other crucial "ways of knowing" required to interact meaningfully with other members of the community. And as they became integrated into the community's fabric, neophytes underwent a gradual process of social transformation in which they acquired an identity as a member of a highly elite and specialized community of practice.

Likewise, the design-and-test cycle provided a site in which more experienced members of the community could demonstrate their skills, validating their expertise and reaffirming their identities as competent members of the weapons community. The long process of designing devices and fielding tests reinscribed linkages among divergent groups of weaponeers, allowed experts to confirm their understandings of weapons work, and gave them a chance to play with established principles, thus affirming and broadening the community's knowledge base. Testing was particularly important in this regard as a ritual process in which a vast and diverse community of experts openly demonstrated their mastery of nuclear technologies by building and detonating a nuclear device. We must understand that nuclear confidence was not based on the repeated testing of stockpiled designs to generate statistically defined parameters of performance. Rather, nuclear confidence was continuously recreated on the boundaries of understanding, as core principles about nuclear weapons were reaffirmed every time weapons experts pushed the limits of communal knowledge to creatively meet military requirements for the devices they were designing. Thus the making of nuclear confidence was an ongoing project that depended on experts stretching boundaries and experimenting with new ideas through building prototype devices and detonating them in the Nevada desert. Making the ground shake was a very dramatic way of generating confidence in the devices, in the designers, in the nation's nuclear deterrent capability. Culminating in a successful test, each iteration of the design-and-test cycle validated the community's claim to a singular sort of expertise: they provided tangible evidence that both the weapons and their creators "worked," that weapons experts could reliably be expected to produce functioning devices and detonate them without mishap in the Nevada desert (Gusterson 1996; Pinch 1991).

At Los Alamos, nuclear devices, communal knowledge, and weapons experts existed as separate but mutually constituted entities that were perpetually reforged in the ongoing iterations of the design-and-test-cycle. Just as the stockpile itself was renewed through the cyclical replacement of its constituent parts with updated weapons systems, so too did the weapons community renew nuclear confidence by reaffirming and extending communal knowledge and by training neophytes to assume the mantle of stockpile steward. Indeed, one can impute a metaphorically 
symbiotic relationship between the stockpile and the Laboratory's weapons community, in the very real sense that neither weapons nor weaponeers could come into existence in the absence of the other.

\section{The End of Time}

As previously discussed, how and when the stockpile would be renewed depended on the extraordinarily complex political machinations that drove the arms race forward. Cold War time, the pace of the arms race, weapons acquisition schedules, the design and testing cycle: all of these ground to a dead halt in the early 1990s, as the framework of bilateral competition that had structured international relations for 45 years melted in the warmth of a new world order. As capricious as international Cold War politics could be, this capriciousness existed within a familiar, relatively predictable structure of competition and "one- upmanship," in which the Soviet Union was an easily-identified enemy, and maintaining a nuclear deterrent was a consistent priority. But as the Cold War drew to a close, the Laboratory found itself struggling for a stable niche in a cosmos gone askew.

At Los Alamos, the end of the Cold War made itself most keenly felt in the cessation of the design and test program, whose termination was precipitated by several trends in the late 1980s and early 1990s: cuts in the national defense budget, the restructuring and consolidation of the nuclear weapons production complex, and Congressional resistance to the acquisition of new weapons systems. These trends came to a collective head in the summer of 1992, when the Bush administration decided to drop orders for several new nuclear weapons packages. At the same time, the administration announced limitations on the number and size of tests that the US nuclear weapons laboratories would be allowed to field. But a Democratic Congress went a step further, attaching an amendment to the 1992 Energy and Water Appropriations Act that called for a nine-month moratorium on nuclear testing. In addition to placing a renewable moratorium on nuclear testing, the socalled Hatfield-Exon-Mitchell Amendment also called for the president to pursue negotiations toward a Comprehensive Test Ban Treaty (CTBT), a longstanding "holy grail" of arms control efforts. Under intense election-year political pressure, President Bush signed the act into law and it went into effect on October 1, 1992.

As a result, none of the three US nuclear weapons laboratories have conducted tests since September 1992, and until the president lifts the current moratorium on nuclear tests, they will not be able to resume testing. Political change notwithstanding, however, the Laboratory is required to certify the devices it has created, year in and year out, for as long as they remain active components of 
the nuclear stockpile. But in doing so, the Laboratory faces problems that it has not previously encountered, including a stockpile of weapons that will no longer be regularly replaced with updated designs, and a community of experts who cannot rely on experiential training to replicate their culture in neophyte weaponeers. Perhaps most critically, however, the cessation of the design and test program means that experts would have to find new ways of generating nuclear confidence and making credible statements about the health and vitality of the nuclear stockpile.

\section{New Ways of Knowing Weapons: Time, Confidence, and Anxiety}

In this paper, I offer the reader a certain way of thinking about the Laboratory's past, framing it as a set of temporal cycles, metaphorically akin to the cogs in a massive knowledge production machine, and ask the reader to consider the complex web of humantechnical relationships that emerged from its workings. As we have seen, the Cold War's end abruptly truncated longstanding cycles of knowledge production. The design and test moratoria held enormous consequence for the weapons community: although the intention was to slow the Cold War arms race, the cessation of the design-and-test program drove a wedge between weapons experts and their devices by halting the Laboratory's primary mechanism for renewing the stockpile, for producing and reaffirming weapons-related knowledge, and for transferring communal knowledge to new members.

Somewhat ironically, the Laboratory's responsibility regarding the nuclear stockpile is one of the few aspects of the community's Cold War existence that remained relatively stable into the post-Cold-War era: as former Laboratory director Siegfried Hecker wrote in 1993, "Our primary mission has not changed. We are still responsible for the stewardship of the nuclear weapons in the enduring US stockpile, and for ensuring the credibility of the nuclear deterrent" (Hecker 1993: 1-2).

Given that the Laboratory's mission has remained stable, the shift away from testing has caused a great deal of stress among members of the weapons community, who remain responsible for annually certifying that stockpiled nuclear weapons will work within specified parameters for safe operation and nuclear yield, and that they cannot be stolen and used by malicious parties. The Cold War's end notwithstanding, the Laboratory's weapons community must certify the weapons it has created, year in and year out, for as long as they will remain active components of the nuclear stockpile.

To fulfill this mission, in 1995 the DOE introduced a new paradigm, the "Stockpile Stewardship and Management" (SSM) program, essentially a new 
system for producing knowledge about weapons without actually producing the devices themselves. As such, SSM relies heavily on the success of its knowledge- production component, the initiative known as Science-Based Stockpile Stewardship (SBSS), under which nuclear weapons research facilities like Los Alamos pursue new, multidisciplinary methods of validating weapon performance without actually creating new designs and in the absence of a full-scale testing program.

In the next section of the paper, I explore how members of the weapons community describe their post-Cold-War mission in regard to the nuclear stockpile. In doing so, I argue that the weapons community is experiencing a shift in its worldview. For over forty years, Cold War weapons work took place in cycles of acquiring, designing, testing, producing, and retiring weapons. However capricious Cold War politics might have been, the cycles of weapons work offered an ongoing process of renewing the stockpile, for training new experts and for extending the boundaries of weapons knowledge. However, this cyclical model of time became inoperative when the Cold War ended. In its place we see a new kind of time emerging, one that is more sequential than its cyclical predecessor. Stretching forward into an unpredictable and murky future, this kind of time offers far fewer opportunities for renewing weapons, experts, or knowledge; and makes questions of age, decay, and death both salient and troublesome.

\section{A World of Threats}

One may very well ask, If nuclear weapons were essentially an artifact of the Cold War, then what is their use now that it has been over for nearly a decade? Understanding the answer to this question gives insight into why the weapons community is so concerned with the effects of time on the stockpile. If the threats of the Cold War were somewhat predictable and structured, then in this new world, threats are capricious, unpredictable, and capable of emerging from any direction, at any time. In a recent DOE film on sciencebased stockpile stewardship, former secretary of state George Schultz was quoted as follows:

The Cold War is over, so we don't have the bipolar structure that we had in those days. But there is widely dispersed power, and one of the difficult things about the world that we live in is that you don't have to be big to get a weapon of mass destruction like a nuclear weapon. So it's an uncertain world, you don't know where your threats are going to come from, and in planning your programs you have to have a long horizon, you have to think ahead, five, ten, twenty years (Schultz quoted in Reis 1999).

To paraphrase Tom Clancy, the Soviet Union was a clear and present danger, but since its dissolution, danger remains but is neither clear nor predictable. 
In this new world, the role of the nuclear expert is to continue producing nuclear confidence-to maintain vigilance over the stockpile, ensuring that it deters threats from such nations as Iraq, Iran, North Korea, Libya, and Israel, all of which have been identified by the DOE as up-and-coming proliferant nuclear nations.

However, the shift from testing to stockpile stewardship means that the process of making confidence is divorced from the process of designing and testing prototypes. In other words, the weapons community will have to develop new ways of making statements about the performance of stockpiled designs without actually designing new weapons, of demonstrating its credibility without making the ground shake. The following two problem statements-both taken from programmatic descriptions of SBSS-describe how the shift from testing to new paradigms for knowledge production are affecting the weapons community's relationship with its devices:

In the past, a large, often renewed, and diverse stockpile provided insurance against... failure and defects compromising the safety and reliability... Nuclear testing could be done to provide unambiguous verification of the effects of design features, material changes, or safety issues... continuous development and production of new systems provided the U.S. Stockpile with the most modem and effective weapons, but also maintained the technical competence of the laboratory in the science and engineering of new weapons... today, none of these conditions exist. (DOE ODP 1995: 3-5).

In the past our mission was accomplished on a large scale with growth. Stockpile systems were periodically replaced with newer and better versions, a robust design and production capacity supported both stockpile modernization and the rapid implementation of stockpile repairs, and confidence was assured with the certainty of an underground nuclear test. (LANL 1997: 1).

The past was a time of confidence, in which weapons knowledge was generated with relative ease through testing-note the use of words like unambiguous, renewed, verification, modern, effective, competence, accomplished, growth, newer, better, robust, capacity, modernization, rapid, confidence, assured, certainty. During the Cold War, time was a force for renewal and confidence, in which the longevity of the stockpile was of little concern since its components could be replaced on a regular basis with updated designs that were thoroughly tested and certified. At the same time, these cycles facilitated the weapons community's ability to maintain and update expertise.

However, now that Cold War cycles no longer serve as mechanisms for renewal, "age" and "death" have emerged as salient and worrisome issues facing both weapons and weaponeers. The language currently used to describe the stockpile points to devices that have become as vulnerable to age as the human experts who designed them: 
Current plans require systems to remain in the stockpile indefinitely, and therefore confidence in the readiness of the stockpile now includes an uncertainty driven principally by aging... Changes resulting from aging are expected in fundamental properties... Aging mechanisms that cause these potential changes include the in-growth of decay products... damage and associated void formation. (LANL 1997: 1-2)

The new lexicon of corrosion uses words like atrophy, aging, and change. In this model, linear time eats away at the vitality of the stockpile, potentially causing life-limiting developments', damage, swelling, instability, embrittlement, vacancies, voids, defects, defect classes, defect clusters, defect sites, defect populations. Once kept healthy through the constant updating of aging systems, specific components of weapons-and therefore the entire stockpile-have suddenly become vulnerable to the ravages of time.

\section{Making Experts}

In the post-Cold-War era, time has become a destabilizing force, one that threatens the longevity of the nuclear explosive devices with forces of age and decay, at the same time that it threatens the ability of the weapons community to replicate its skills in a new generation. Being able to make confident statements about the performance of the stockpile required an intimate familiarity with the complexities of nuclear devices, a familiarity that weapons experts once attained through participating in repeated iterations of the nowdefunct design and test cycle:

In the past, continuous development and production of new weapons maintained the scientific and technical knowledge and skill base essential for maintaining the safety and reliability of the stockpile. With no new weapons in development or production, budget reductions, and an aging staff with actual experience in designing, testing and producing nuclear weapons, the knowledge and skill base unique to nuclear weapons will atrophy (DOE ODP 1997: 5).

Robert, a senior weapon designer, told me the following:

For reasons I don't entirely understand, weapons design never got the hallmarks of a true profession. Lawyers have the bar exam, doctors have medical boards, but we don't have anything like that. Why? Because it was understood that important people were tested by nuclear test experience. Now we've lost that... Once a year, experts from Sandia, Livermore, Los Alamos, the DOE, StratCom come together to certify that nuclear weapons will function, that we don't need to test anymore... The certification event has replaced the testing program. But it's a paper exercise and it doesn't answer the most important question: Who certifies the [experts], and in the 
future, who will certify their replacements? We might have a cadre [of experts] now, but we won't have them forever. ${ }^{1}$

The question, then, is how to establish new ways of making knowledge about nuclear weapons that, at the same time, will confirm that new members of the community have the expertise necessary to make competent judgements about the state of the stockpile.

But just as the process for making experts and making knowledge is changing, so too is the role of the designer. As we have seen, the Los Alamos weapons community reinscribed its mastery of nuclear knowledge, and thereby produced nuclear confidence, in the process of designing and testing new devices. But in this new model of knowledge production, designers are no longer inventors. Rather, they are analysts or assessors. As one member of the Laboratory's secondary design group put it, "We're not designers anymore and some people around here don't like that idea. We are assessors." Robert later underscored this point: "Today we have analysts. There's always some question about a bomb in the stockpile; we want to determine the effect of a defect on the performance of a warhead. So we analyze, we make judgements about whether the defect is important enough to matter."

Borrowing the terms used in programmatic descriptions of SBSS to describe the state of the stockpile and the weapons community, we can create the following model of weapons work in the post-Cold-War era:

Weaponeers must (predict, model, assess, perform surveillance, simulate, diagnose, evaluate, anticipate, understand) weapon behavior using (age-focused/age aware simulations, models) to understand the behavior of a stockpile of weapons that face problems of (aging, decay, decay products, damage, void, instability, change, defects, decay-induced change, swelling, embrittlement, vacancies, vacancy clusters, voids, defect sites, defect populations). Weapons face an (extended service-life, extend lifetimes, aging processes, beyond original or intended design life, unknown time) in a future characterized by (uncertainty, danger, unpredictability, concerns, threats, failure, the unknown, weakness).

The shift from one temporal model to another has significant implications for the weapons community's mission regarding the stockpile: the end of the Cold War revealed that cyclical time and confidence were intimately partnered, in the sense that confidence in both the stockpile and the weapons community depended on constant renewal and recreation of both weapons and experts through the ongoing iterations of the design-and-test cycle. In this new world, the weapons community must develop predictive capabilities that extend

\footnotetext{
${ }^{1}$ Interviewees are given pseudonyms to protect their anonymity.
} 
communal knowledge into an unpredictable and murky future, providing certainty for a new time in which the once eternally youthful stockpile is now filled with weapons that age, decay, and face the possibility of death.

\section{References}

Barley, S. 1988. "On Technology, Time and Social Order: Technically Induced Change in the Temporal Organization of Radiological Work," pp. 123-174 in Frank Dubinskas, ed. Making Time: Ethnographies of High Technology Organizations (Temple University Press, Philadelphia, PA).

Birely, J. 1987. The Issue of Nuclear Testing. Center for National Security Studies (Los Alamos, NM: Los Alamos National Laboratory).

Bucciarelli, L. 1988. "Engineering Design Process,” pp. 92-122 in Frank Dubinskas, ed. Making Time: Ethnographies of High Technology Organizations (Temple University Press, Philadelphia, PA).

Cimbala, S J. 1998. "The Nuclear Chimera: How Deterrence Really Worked,” pp. 11-35 in The Past and Future of Nuclear Deterrence (Praeger Publishers, Westport, CT).

Dubinskas, F. 1988. "Cultural Constructions: The Many Faces of Time," pp. 3-38 in Making Time: Ethnographies of High Technology Organizations (Temple University Press, Philadelphia, PA).

Gusterson, H. 1996. Nuclear Rites: A Weapons Laboratory at the End of the Cold War, (University of California Press Berkeley and Los Angeles, CA).

Hecker, S S. 1987. Statement before the Senate Armed Services Committee Concerning TTBT and PNET Ratification, $100^{\text {th }}$ Congress, $1^{\text {st }}$ Session. February $26^{\text {th }}$.

. 1993. Director's Statement, pp. 1-1 to 1-5 in Los Alamos National Laboratory:

Institutional Plan, FY1993-FY1998, Los Alamos National Laboratory report LALP- 9250 (Los Alamos, NM).

Johnson, K, J Keller, C Ekdahl, R Krajcik, L Salazar, E Kelly, and R Paulsen. 1996. Stockpile Surveillance: Past and Future, Sandia National Laboratories SAND-95- 2751 (Albuquerque, NM).

Lave, J. 1988. Cognition in Practice, (Cambridge University Press, Cambridge, UK). Lave, Jean, and Etienne Wenger. 1991. Situated Learning: Legitimate Peripheral

Participation (Cambridge University Press, Cambridge, UK).

Lawrence Livermore National Laboratory. 1985. Nuclear Test Program, Lawrence Livermore National Laboratory Report LLL-TB-57 (Livermore, California) and the U.S. Government Printing Office (Washington, DC).

Los Alamos National Laboratory. 1997. Enhanced Surveillance Program: FY 1997 Accomplishments, Los Alamos National Laboratory report LA-13363-PR (Los Alamos, NM).

Mackenzie, D, and G Spinardi. 1995. "Tacit Knowledge, Weapons Design, and the Uninvention of Nuclear Weapons," American Journal of Sociology 101 (1), 44-99. 
Pinch, T. 1991. "Testing-One, Two, Three ... Testing: Towards a Sociology of Testing," in Science, Technology and Human Values 18 (1), 25-41.

Reis, V. 1999. "The Race Against Time," from All Hands Employee Meeting, 26 July, Los

Alamos National Laboratory videorecording with embedded video 99-209 (Los Alamos, NM).

Traweek, S. 1988a. Beamtimes and Lifetimes: the World of High Energy Physicists (Harvard University Press, Cambridge, MA).

. 1988b. "Discovering Machines: Nature in the Age of its Mechanical

Reproduction," pp. 39-91 in Frank Dubinskas, ed., Making Time: Ethnographies of High Technology Organizations (Temple University Press, Philadelphia, PA).

United States Congress, Office of Technology Assessment. 1989. The Containment of Underground Nuclear Explosions, OTA-ISC-414 (U.S. Government Printing Office, Washington, DC).

United States Department of Energy, Office of Defense Programs. May 1995. The Stockpile Stewardship and Management Program: Maintaining Confidence in the Safety and Reliability of the Enduring U.S. Nuclear Weapon Stockpile (U.S. Government Printing Office, Washington, DC, available online at http://stsfac.mit.edu/proiects/sbss/ doe.html.f Van Cleave, W R., and S.T. Cohen. 1987. Preface, Nuclear Weapons, Policies and the Test Ban Issue (Praeger Publishers, Westport, CT).

Wenger, E. 1998. Communities of Practice: Learning, Meaning and Identity (Cambridge University Press, Cambridge, UK).

White, P. 1987a. United States National Security Policy and Laboratory Nuclear Weapon Development: Statement to the Senate Committee on Health and Human Services, State of California Legislature, February 11, the Center for National Security Studies, Los Alamos National Laboratory document (Los Alamos, NM).

. 1987b. Test Bans, Legislation and Arms Control, the Center for National Security

Studies, Los Alamos National Laboratory document (Los Alamos, NM) June 23.

. 1988. Observations on the Nuclear Test Ban Debate, the Center for National

Security Studies, Los Alamos National Laboratory document (Los Alamos, NM) August 3.

Wolff, W. 1977. A Typical LASL Underground Nuclear Test, Los Alamos Scientific Laboratory report (Los Alamos, NM). 